\title{
Efficacy of a respiratory rehabilitation exercise training package in hospitalized elderly patients with acute exacerbation of COPD: a randomized control trial
}

\author{
This article was published in the following Dove Press journal: \\ International Journal of COPD \\ 27 August 2015 \\ Number of times this article has been viewed
}

\author{
Lin-Yu Liao ${ }^{1,2}$ \\ Kuei-Min Chen ${ }^{2}$ \\ Wei-Sheng Chung ${ }^{3}$ \\ Jung-Yien Chien ${ }^{4}$
}

'Department of Nursing, Chest Hospital, Ministry of Health and Welfare, Rende District, Tainan, ${ }^{2}$ College of Nursing, Kaohsiung Medical University, Sanmin District, Kaohsiung, ${ }^{3}$ Department of Internal Medicine, Taichung Hospital, Ministry of Health and Welfare, Taichung, ${ }^{4}$ Department of Medicine, Chest Hospital, Ministry of Health and Welfare, Rende District, Tainan, Taiwan

\begin{abstract}
Clinical trials identifier: NCT02329873
Background: Acute exacerbation (AE) of COPD is characterized by a sudden worsening of COPD symptoms. Previous studies have explored the effectiveness of respiratory rehabilitation for patients with COPD; however, no training program specific to acute exacerbation in elderly patients or unstable periods during hospitalization has been developed.
\end{abstract}

Objective: To evaluate the effects of a respiratory rehabilitation exercise training package on dyspnea, cough, exercise tolerance, and sputum expectoration among hospitalized elderly patients with AECOPD.

Methods: A randomized control trial was conducted. Pretest and posttest evaluations of 61 elderly inpatients with AECOPD (experimental group $n=30$; control group $n=31$ ) were performed. The experimental group received respiratory rehabilitation exercise training twice a day, 10-30 minutes per session for 4 days. The clinical parameters (dyspnea, cough, exercise tolerance, and sputum expectoration) were assessed at the baseline and at the end of the fourth day.

Results: All participants (median age $=70$ years, male $=60.70 \%$, and peak expiratory flow $140 \mathrm{~L}$ ) completed the study. In the patients of the experimental group, dyspnea and cough decreased and exercise tolerance and sputum expectoration increased significantly compared with those of the patients in the control group (all $P<0.05$ ). Within-group comparisons revealed that the dyspnea, cough, and exercise tolerance significantly improved in the experimental group by the end of the fourth day (all $P<0.05$ ).

Conclusion: Results of this study suggest that the respiratory rehabilitation exercise training package reduced symptoms and enhanced the effectiveness of the care of elderly inpatients with AECOPD.

Keywords: COPD, severe early onset, exercise, older adults, respiratory diseases

\section{Introduction}

Acute exacerbation (AE) of AECOPD is characterized by a sudden worsening of COPD symptoms. Older adults with COPD have a high risk of experiencing AECOPD, ${ }^{1}$ which typically leads to a decreased lung function, an increased incidence of respiratory failure, and even death. ${ }^{2,3}$ Patients with COPD who experience aggravation of symptoms, such as dyspnea, cough, and sputum production, for $>48$ hours are diagnosed with AECOPD. ${ }^{3,4}$ Dyspnea, coughing, difficulties in sputum clearance, and low exercise tolerance are systemic symptoms in patients with AECOPD. ${ }^{5,6}$

Pharmacological therapy and respiratory rehabilitation exercise management constitute the standard treatment for COPD. ${ }^{2}$ According to the guidelines for global COPD care, 
pharmacological treatment involves antibiotics, bronchodilators, and steroids. Airway clearance devices and oxygen therapy are sometimes used in patients with acute exacerbation. ${ }^{7}$ In the progression of AECOPD, poor exercise tolerance could be caused by prolonged bed rest during hospitalization, exposure to high dosage of glucocorticoids, ${ }^{8}$ and negative protein balance, which are due to the insufficient dietary intake and increased resting energy expenditure during acute exacerbation. ${ }^{9}$ Although the aforementioned drugs can treat AECOPD, they have side effects and, thus, reduce patients' willingness to move, contributing to adverse effects on physical and mental health, ${ }^{10}$ and ultimately leading to patient readmission. ${ }^{11}$

Clini et al indicated that rehabilitation exercises performed during hospitalization effectively ameliorate AECOPD symptoms, improve quality of life, and increase exercise tolerance. ${ }^{12}$ Greening et al found that rehabilitation intervention within 48 hours of hospital admission improved muscle strength, field walking performance, and rapid recovery of endurance walking after discharge. ${ }^{13}$ Previous studies have reported that respiratory rehabilitation exercise performed within 2 weeks of disease onset (unstable period) alleviates acute symptoms to a greater extent than does the exercise performed 6 months after disease onset (stable period). ${ }^{14}$ According to an American Thoracic Society/European Respiratory Society statement, pulmonary rehabilitation is a comprehensive intervention that includes exercise training, education, and behavioral changes. ${ }^{15}$ Rehabilitation approach includes 1) upper-limb exercise training for increasing maximal exercise capacity, decreasing dyspnea, and reducing fatigue, ${ }^{16,17}$ 2) pursed lip breathing (PLB) for increasing the respiratory coordination of the diaphragm and inspiratory muscle strength, reducing coughing frequency, dyspnea, and hypoxemia symptoms, and facilitating sputum clearance, ${ }^{18,19}$ 3) treadmill exercises for enhancing cardiopulmonary functions and weight training for improving muscles of the legs, ${ }^{12}$ 4) airway clearance (such as chest percussion and postural drainage) for transferring the sputum into the main bronchi and, consequently, increasing sputum expectoration, ${ }^{20,21}$ and 5) smoking cessation, health education, and self-health management. ${ }^{12}$ These measures are often provided to stable patients or after discharge through individual routine nursing care, 22 however, no training program specific to acute exacerbation in elderly patients or unstable periods during hospitalization has been developed.

This study involved developing a respiratory rehabilitation exercise training package for inpatients with AECOPD. Interdisciplinary care processes were incorporated into the design of the rehabilitation exercises, and instructional tools were developed. The efficacy of the intervention in reducing AECOPD symptoms (such as dyspnea and cough), increasing exercise tolerance, and sputum expectoration in elderly inpatients was evaluated.

\section{Methods Design}

This study was a randomized controlled trial in which purposive sampling was conducted to recruit patients who were randomized to the respiratory rehabilitation exercise training package (experimental) group or the control group, according to a coin toss. To prevent mutual interference, the patients in the experimental and control groups were assigned to wards located in different areas (east and west wings) upon admission. The experimental group received 4 days of respiratory rehabilitation exercise training in addition to the usual care and health education. The control group only received usual care and health education, which included monitoring of the vital signs and the AECOPD symptoms, assessing the nutritional status, educating the smoking cessation, and providing the nasal $\mathrm{O}_{2}$ therapy. One hour before the intervention, the patients were assessed for dyspnea, cough, exercise tolerance, and sputum expectoration. The pretest results served as the baseline data. Posttest measurements were completed within 1 hour after the final intervention session.

\section{Setting and participants}

The study was conducted in two pulmonary wards of the Chest Hospital, Ministry of Health and Welfare, in Southern Taiwan. Sixty-two patients were recruited of which 31 were assigned to the respiratory rehabilitation exercise training package (experimental) group and 31 were assigned to the control group. One experimental group participant withdrew from the study due to discharge (Figure 1). Sample size calculation was based on previous studies, ${ }^{23}$ and we estimated that a sample of $60($ experimental $=30$, control $=30)$ would have $80 \%$ power to detect a $35 \%$ difference in the dyspnea score.

Inclusion criteria stipulated that the participants should have the following five characteristics: 1) had been diagnosed with moderate exacerbation COPD (an increased need for medication and feel the need to seek additional medical assistance), ${ }^{4}$ 2) were older than 65 years; 3 ) were in clear consciousness, 4) had been diagnosed with shortness of breath or dyspnea that was not caused by heart disease, pneumothorax, or pulmonary edema, and 5) had received bronchodilator aerosol therapy or antibiotic treatment, but had not been treated with an antitussive. Exclusion criteria were 1) systolic blood pressure lower than $90 \mathrm{mmHg}, 2$ ) a 


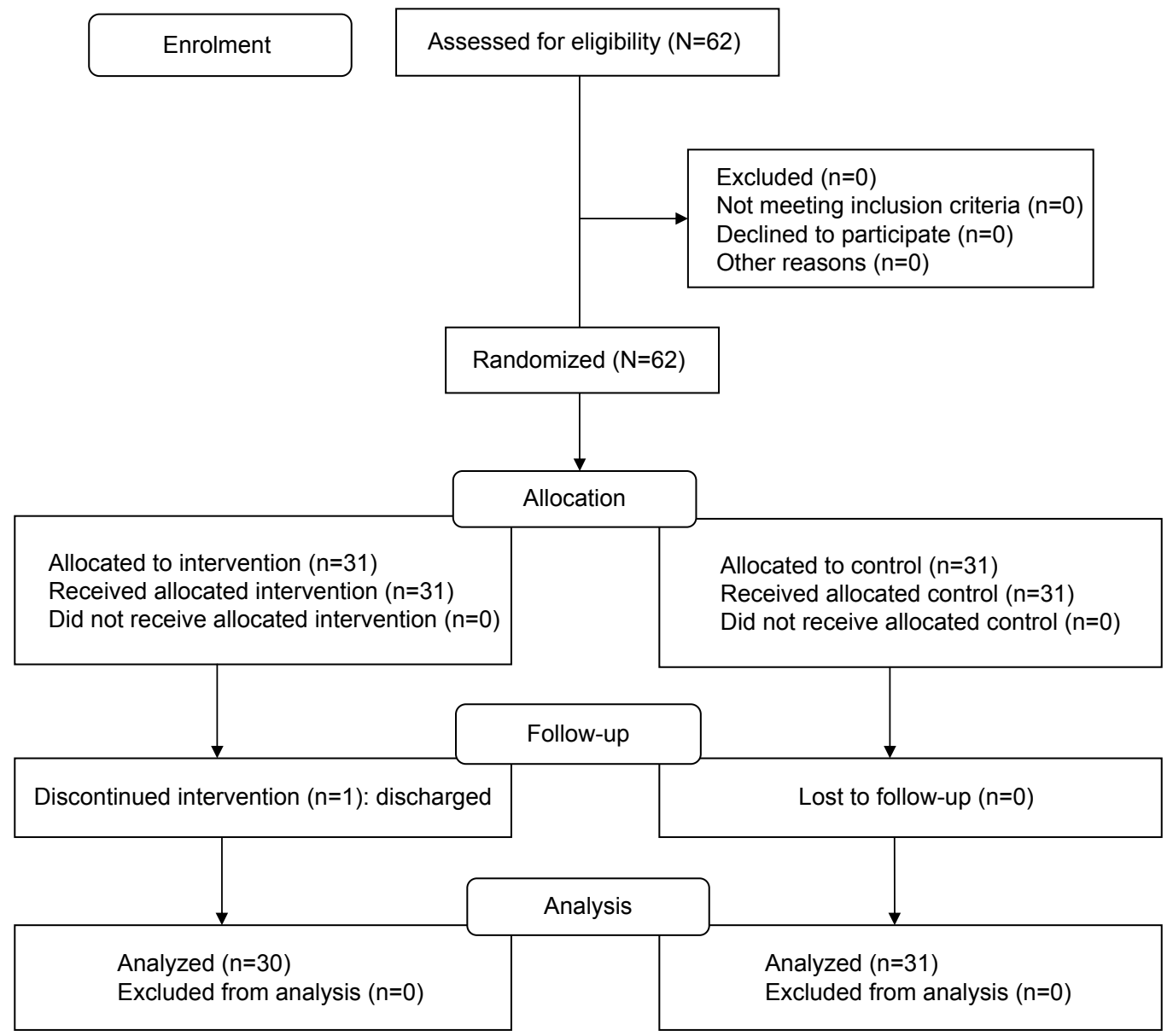

Figure I Flowchart of the Participants' Selection Process of the Study.

blood oxygen concentration lower than $\mathrm{SpO}_{2}=90 \%$, and 3) an unstable psychological status, hemoptysis, pneumothorax, pulmonary edema, and the use of a respirator.

\section{Ethical considerations}

The study was approved by the Institutional Review Board of National Chen Kung University Hospital, Taiwan (ER-100202). The principal investigator explained to the patients the objectives, implementation process, inclusion criteria, and exclusion criteria of the study. In addition, the patients were informed that they could withdraw from the study at any time if they felt unwell, and they were enrolled only after signing informed consent forms.

\section{Intervention}

The respiratory rehabilitation exercise training package intervention has the following six components: 1) disease awareness: the physician explained AECOPD to patients and their families by using a chest X-ray. Pulmonary anatomic illustrations were then attached to the hand over shift card assigned to each patient to inform the nurses of pulmonary lesion sites, thus facilitating disease awareness; 2) sputum clearance treatments: easily understood postural drainage cards were provided to the patients and family members and hung near patients' hospital beds to enable assistance with proper sputum clearance procedures. Instructions on the cards explained how to properly place the vibrating sputum clearance devices at the correct asymptomatic sites for performing back percussion and positioning for postural drainage. The vibrating sputum clearance devices were manufactured by the General Physiotherapy, Inc. (Earth City, MO, USA), and a permit for their use was obtained from the Department of Health in Taiwan (Health Department Medical Device no 021492). Sputum clearance treatments were conducted for 30 minutes twice per day; 3) PLB training: PLB devices designed by the authors were provided to the patients to ensure that the PLB rehabilitation exercises were completed properly. Using this device prevented carbon dioxide accumulation in the lungs, which affects oxygenation. The ratio of inspiratory to expiratory breathing was 1:2. This device 
was used at least twice per day for 10 minutes per session; ${ }^{18,19}$ 4) upper-limb exercise with deep breathing: towels were provided to the patients to support the movement of the upper limbs and enable them to complete upper-limb exercises properly. This exercise was performed by inhaling when the arms were raised and exhaling when the arms were lowered. In addition to expanding the chest, this exercise enhances respiratory muscle strength and facilitates sputum expectoration. This upper-limb rehabilitation exercise was conducted a minimum of twice per day for 10 minutes per time; ${ }^{16} 5$ ) walk training: patients walked back and forth in the ward corridor with a minimum of twice per day for 10 minutes per time. Walking training was conducted by inhaling when the patients raised their legs and exhaling when they lowered their legs; and 6) assigned pulmonary rehabilitation program coordinator: coordinators were assigned to assist patients in nutrition management and health education (eg, education on diseases, smoking cessation, medication, sputum clearance techniques). These sessions were conducted a minimum of twice per day for 10 minutes per session. These components were conducted by the nurses, except the first component, which was done by the physician.

\section{Data collection}

Data were collected from November 2011 to April 2012. A researcher who collected the data was different from the researcher who administered the intervention. The data collector was further blinded as to the allocation of the patients to the two groups. Four outcome variables were tested, such as dyspnea, cough, exercise tolerance, and sputum expectoration.

\section{Demographic data}

Patient's demographic data, such as age, body height, body weight, body mass index, educational level, marital status, smoking history, medical history, and peak expiratory flow, were collected. According to Chow et al one of the best ways to measure lung function was the peak expiratory flow. ${ }^{24}$

\section{Dyspnea}

The Modified Borg Scale for Perceived Dyspnea, in which respondents report their exertion level after walking for 6 minutes on a scale ranging from 0 (lowest exertion) to 10 (highest exertion), was used to measure the dyspnea of the patients. ${ }^{25}$ The reliability of dyspnea degree after exercising was up to $0.92 .{ }^{26}$ In this study, Cronbach's alpha was 0.78 .

\section{Cough}

This study assessed the average degree of coughing during the previous day. Cough severity was measured using a visual analog scale, a straight line of $0-10$ points $(0=$ no coughing, $10=$ severe coughing) on which respondents indicate cough severity. ${ }^{27}$ In this study, Cronbach's alpha was 0.70 .

\section{Exercise tolerance}

The 6-minute walk distance was used to assess exercise tolerance. The patients wore comfortable shoes and clothes and walked on a hard, flat surface. The total length of the surface was $30 \mathrm{~m}$, and the patients walked for 6 minutes. ${ }^{28,29}$ Before the test, the patients were allowed 15 minutes of rest, and a physical examination was conducted to measure heart rate, blood pressure, respiratory rate, blood oxygen saturation, and dyspnea index. The patients could stop and rest during the test if they experienced shortness of breath. After the conclusion of 6-minute walk, the patients stayed in their positions on the floor in order to measure the total walking distance. ${ }^{28,29}$

\section{Sputum expectoration}

Sputum expectoration was assessed by the difficulty level of sputum clearance in the morning. Participants were asked to reflect whether it was difficult or easy to expectorate the sputum.

\section{Data analysis}

After the data were collected, coded, inputted into the computer, and verified, the SPSS Version 17.0 for Windows was used for analysis. Since the data were not normally distributed, the nonparametric statistics were used to analyze the data. The frequency distribution, percentage, median, and range were used to describe the demographic profiles of the participants. The Mann-Whitney $U$-test was used for measuring continuous variables, and the chi-square test was used for measuring categorical variables to determine whether significant differences in the baseline data existed between the experimental and the control groups. The Wilcoxon $W$ test or McNemar test was conducted to measure the changes of dyspnea, cough, exercise tolerance, and sputum expectoration in the two groups before and after the intervention. The level of significance was set as $P<0.05$.

\section{Results}

Demographic profiles of the participants and their baseline comparisons

In total, 61 elderly inpatients (experimental group, $n=30$; control group, $n=31$ ) completed the study requirements. Only one experimental group participant withdrew from the study 
Table I Demographic profiles of the participants $(\mathrm{N}=6 \mathrm{I})$

\begin{tabular}{|c|c|c|c|c|}
\hline \multirow[t]{3}{*}{ Variables } & \multicolumn{2}{|c|}{ Experiment $(n=30)$} & \multicolumn{2}{|c|}{ Control $(n=3 I)$} \\
\hline & Median & Range & Median & Range \\
\hline & (n) & (\%) & (n) & (\%) \\
\hline Age (years) & 68.0 & $44.0-89.0$ & 70.0 & $52.0-91.0$ \\
\hline BMI $\left(\mathrm{kg} / \mathrm{m}^{2}\right)$ & 23.9 & |5.7-34.| & 24.0 & $17.0-35.0$ \\
\hline PEF (L/second) & 140.0 & $50.0-240.0$ & 140.0 & $60.0-300.0$ \\
\hline \multicolumn{5}{|l|}{ Sex } \\
\hline Male & $(16)$ & $(53.3)$ & $(2 I)$ & $(67.7)$ \\
\hline Female & (14) & $(46.7)$ & (I0) & (32.3) \\
\hline \multicolumn{5}{|l|}{ Marital status } \\
\hline No & $(0)$ & $(0)$ & (3) & $(9.7)$ \\
\hline Yes & (30) & $(100)$ & (28) & $(90.3)$ \\
\hline \multicolumn{5}{|l|}{ Educational level } \\
\hline Illiterate & $(10)$ & (33.3) & (7) & $(22.6)$ \\
\hline Elementary school & (I5) & $(50.0)$ & (19) & $(61.3)$ \\
\hline High school & (5) & $(16.7)$ & (5) & $(16.1)$ \\
\hline \multicolumn{5}{|l|}{ Medical comorbidity } \\
\hline No & $(0)$ & $(0)$ & (3) & $(9.7)$ \\
\hline Yes & (30) & $(100)$ & (28) & $(90.3)$ \\
\hline \multicolumn{5}{|l|}{ Smoking status } \\
\hline No & $(20)$ & $(66.7)$ & (I5) & $(48.4)$ \\
\hline Yes & $(10)$ & $(33.3)$ & (16) & $(51.6)$ \\
\hline
\end{tabular}

Abbreviations: BMI, body mass index; PEF, peak expiratory flow.

owing to discharge. The median age of these participants was 70 (range $=44-91$ ) years. The median body mass index and peak expiratory flow of the participants were $24 \mathrm{~kg} / \mathrm{m}^{2}$ (range $=15.7-35.0)$ and $140 \mathrm{~L}$ (range $=50-300)$, respectively . Most of the participants were male $(60.7 \%)$ and married (95.1\%), and more than half (55.7\%) had a 6-year elementary school education. Most of the participants had medical comorbidity (62.7\%); however, more than half $(57.4 \%)$ of them did not smoke. As shown in Table 1, no significant differences existed between the experimental and control groups in all of the demographic profiles $(P>0.05)$. In terms of the baseline comparisons, no significant differences occurred in the variables of dyspnea, cough, exercise tolerance, and sputum expectoration either (all $P>0.05$ ) (Tables 2 and 3 ).

\section{Between-group and within-group comparisons}

By the end of the fourth-day study, the experimental group participants had less degree of dyspnea $(U=-2.99, P=0.003)$, fewer frequency of coughing $(U=-3.64, P<0.001)$, greater exercise tolerance $(U=-3.68, P<0.001)$, and better sputum expectoration (McNemar $=4.43, P=0.034)$ than the control group participants (Tables 2 and 3 ).

In the within-group comparisons, the experimental group participants had significant alleviations in the symptoms of dyspnea ( $W=-4.35, P<0.001$ ), coughing ( $W=-4.30$, $P<0.001)$, and significant improvements in exercise tolerance $(W=-4.53, P<0.001)$ after 4 days of the intervention. However, no significant change was found in the sputum expectoration $(\mathrm{McNemar}=0.08, P=0.621$ ) of the experimental group participants after 4 days of the intervention. In terms of the control group participants, no significant changes were observed in all of the variables $(P>0.05)$, except the sputum expectoration $(\mathrm{McNemar}=4.78, P=0.036)($ Tables 2 and 3$)$.

\section{Discussion}

Results indicated that the respiratory rehabilitation exercise training package significantly alleviated dyspnea and cough and increased the exercise tolerance in hospitalized elderly patients with AECOPD. In addition, all of the AECOPD symptoms of the participants in the experimental group were less severe than were those in the control group at the end of the fourth day of study. These results were consistent with those studies that involved providing respiratory rehabilitation exercise training to inpatients ${ }^{30}$ and outpatients, ${ }^{22}$ showing

Table 2 Between and within groups differences on dyspnea, cough, and exercise tolerance at baseline and the end of fourth day $(\mathrm{N}=6 \mathrm{I})$

\begin{tabular}{|c|c|c|c|c|c|c|}
\hline \multirow[t]{2}{*}{ Variables } & \multicolumn{2}{|c|}{ Experiment $(\mathrm{n}=30)$} & \multicolumn{2}{|c|}{ Control $(n=3 I)$} & \multirow[t]{2}{*}{ Between-group test } & \multirow[t]{2}{*}{$P$-value } \\
\hline & Median & Range & Median & Range & & \\
\hline \multicolumn{7}{|l|}{ Dyspnea } \\
\hline Baseline & 5 & $0-8$ & 4 & $0-10$ & $-0.76^{\mathrm{a}}$ & 0.448 \\
\hline At the fourth day & I & $0-4$ & 4 & $0-10$ & $-2.99^{a}$ & $0.003 * *$ \\
\hline Within-group test ( $P$-value) & \multicolumn{2}{|c|}{$-4.35\left(<0.00 I^{* * *}\right)^{\mathrm{b}}$} & \multicolumn{2}{|c|}{$-1.69(0.09 \mathrm{I})^{\mathrm{b}}$} & & \\
\hline \multicolumn{7}{|l|}{ Cough } \\
\hline Baseline & 5 & $0-10$ & 5 & $0-10$ & $-\left.0.3\right|^{\mathrm{a}}$ & 0.760 \\
\hline At the fourth day & 2 & $0-5$ & 4 & $0-10$ & $-3.64^{a}$ & $<0.00 I^{* * *}$ \\
\hline Within-group test ( $P$-value) & \multicolumn{2}{|c|}{$-4.30\left(<0.00 I^{* * * *}\right)^{\mathrm{b}}$} & \multicolumn{2}{|c|}{$-1.65(0.099)^{\mathrm{b}}$} & & \\
\hline \multicolumn{7}{|l|}{ Exercise tolerance $(\mathrm{m})$} \\
\hline Baseline & 160 & $50-390$ & 200 & $60-290$ & $-1.28^{\mathrm{a}}$ & 0.200 \\
\hline At the fourth day & 280 & $80-390$ & 200 & $60-375$ & $-3.68^{a}$ & $<0.00 I^{* * *}$ \\
\hline Within-group test ( $P$-value) & \multicolumn{2}{|c|}{$-4.53\left(<0.00 I^{* * *}\right)^{\mathrm{b}}$} & \multicolumn{2}{|c|}{$0.81(0.419)^{b}$} & & \\
\hline
\end{tabular}

Notes: a Mann-Whitney U-test; ${ }^{b}$ Wilcoxon $W$ test; ${ }^{* *} P<0.01$; $* * * P<0.001$. 
Table 3 Between and within groups differences on sputum expectoration at baseline and the end of fourth day $(\mathrm{N}=6 \mathrm{I})$

\begin{tabular}{|c|c|c|c|c|c|c|}
\hline \multirow[t]{2}{*}{ Variables } & \multicolumn{2}{|c|}{ Experiment $(n=30)$} & \multicolumn{2}{|c|}{ Control $(n=31)$} & \multirow{2}{*}{$\begin{array}{l}\text { Between-group } \\
\text { test }\end{array}$} & \multirow[t]{2}{*}{$P$-value } \\
\hline & $\mathbf{N}$ & $\%$ & $\mathbf{N}$ & $\%$ & & \\
\hline \multicolumn{7}{|l|}{ Sputum expectoration } \\
\hline Baseline & & & & & $0.97^{\mathrm{a}}$ & 0.162 \\
\hline Difficult & 8 & 26.7 & 13 & 41.9 & & \\
\hline Easy & 22 & 73.3 & 18 & 58.9 & & \\
\hline At the fourth day & & & & & $4.43^{\mathrm{a}}$ & $0.034 *$ \\
\hline Difficult & 3 & 10.0 & 10 & 32.3 & & \\
\hline Easy & 27 & 90.0 & 21 & 67.7 & & \\
\hline Within-group test ( $P$-value) & \multicolumn{2}{|c|}{$0.08(0.621)^{\mathrm{a}}$} & \multicolumn{2}{|c|}{$4.78\left(0.036^{*}\right)^{\mathrm{a}}$} & & \\
\hline
\end{tabular}

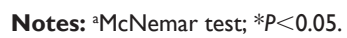

that respiratory rehabilitation exercise training maintained a healthy state and alleviated acute clinical symptoms in older adults with AECOPD. However, the experimental group participants showed no significant changes in the sputum expectoration after 4 days of intervention, on the other hand, a significant improvement was observed in the control group. Lareau and Yawn stated that smoking leads to chronic lung inflammation and induces poor lung function, and difficult exacerbation. ${ }^{31}$ Regarding the demographic profiles of the participants, more smokers were in the control group than in the experimental group. Moreover, the patients in the control group may have had a higher susceptibility to sputum, which was related to smoking and impairment of lung function and chronic lung inflammation. ${ }^{31}$ Thus, control group patients might have more deep feelings after quit smoking.

The respiratory rehabilitation exercise training intervention was implemented for only 4 days in our study, and the results showed significant intervention efficacy, which confirmed previous research findings on early rehabilitation intervention upon admission. ${ }^{13}$ This exercise training package was designed by integrating the opinions of various specialists and considering the pathological mechanisms of AECOPD symptoms. The exercise training package should be delivered during standard nursing care and involves disease awareness, sputum clearance treatments, PLB training, upper-limb exercise with deep breathing, walk training, and a pulmonary rehabilitation program coordinator. The design was consistent with the design in previous studies, in which standard medical care enhanced exercise tolerance ${ }^{32}$ and reduced dyspnea. ${ }^{33}$

This study also showed that intervention using PLB devices was more effective than intervention in which no devices were used. A towel was used to enhance the arm lift balance, when the chest was fully extended. Hanging postural drainage cards at the bedside enabled the elderly inpatients to learn the correct postural drainage method and how to use chest percussion equipment correctly to increase the efficiency of sputum clearance. The experimental group achieved more positive results than the control group. Hence, the results of our study provide insight into the efficacy of the designed respiratory rehabilitation exercise training package in enhancing the learning of elderly inpatients with AECOPD and promoting nurse education.

\section{Study limitations}

Although benefits of the respiratory rehabilitation exercise training package were manifested in our study, some limitations should be acknowledged. First, the sample was too small to enable generalization of the results to other elderly inpatients with AECOPD. Second, the participants were followed for only 4 days, and all variables were measured at baseline and at the end of the fourth day. Consequently, the variation during and after the 4-day course was not observed. In other words, the short follow-up time and insufficient measurement frequency were of concern. Finally, the sputum expectoration was measured subjectively, which might have the recall bias. More objective measurements with good psychometric properties should be applied in the future studies.

\section{Conclusion}

The respiratory rehabilitation exercise training package reduced AECOPD symptoms (such as dyspnea and cough), increased exercise tolerance, and sputum expectoration in elderly inpatients. Furthermore, postural drainage cards and percussion equipment, PLB devices, and towels used during upper-limb exercise improved the respiratory rehabilitation skills of the participants. Future studies can evaluate the effectiveness of delivering the respiratory rehabilitation exercise training package early in reducing the acute episode rate, readmission rate, and number of hospitalization days in patients with AECOPD.

\section{Acknowledgments}

We would like to thank the staff at the Chest Hospital, Ministry of Health and Welfare for their support and 
assistance required for completing this study. This study was funded by the Chest Hospital, Ministry of Health and Welfare, Taiwan (DOH100-HO-3053).

\section{Disclosure}

The authors report no conflicts of interest in this work.

\section{References}

1. Jurado Gámez B, Feu Collado N, Jurado García JC, et al. Home intervention and predictor variables for rehospitalization in chronic obstructive pulmonary disease exacerbations. Arch Bronconeumol. 2013;49(1):10-14.

2. Johnson MK, Stevenson RD. Management of an acute exacerbation of copd: are we ignoring the evidence? Thorax. 2002;57(suppl 2): II15-II23.

3. MacIntyre N, Huang YC. Acute exacerbations and respiratory failure in chronic obstructive pulmonary disease. Proc Am Thorac Soc. 2008; 5(4):530-535.

4. Rodriguez-Roisin R. Toward a consensus definition for COPD exacerbations. Chest. 2000;117(5 suppl 2):398S-401S

5. Burge S, Wedzicha JA. COPD exacerbations: definitions and classifications. Eur Respir J. 2003;41:46s-53s.

6. Carr SJ, Goldstein RS, Brooks D. Acute exacerbations of COPD in subjects completing pulmonary rehabilitation. Chest. 2007;132(1):127-134.

7. Vestbo J, Hurd SS, Agustí AG, et al. Global strategy for the diagnosis, management, and prevention of chronic obstructive pulmonary disease: GOLD executive summary. Am J Respir Crit Care Med. 2013;187(4):347-365.

8. Spruit MA, Gosselink R, Troosters T, et al. Muscle force during an acute exacerbation in hospitalised patients with COPD and its relationship with CXCL8 and IGF-I. Thorax. 2003;58(9):752-756.

9. Vermeeren MA, Schols AM, Wouters EF. Effects of an acute exacerbation on nutritional and metabolic profile of patients with COPD. Eur Respir J. 1997;10(10):2264-2269.

10. Pitta F, Troosters T, Probst VS, Spruit MA, Decramer M, Gosselink R. Physical activity and hospitalization for exacerbation of COPD. Chest. 2006;129(3):536-544.

11. Garcia-Aymerich J, Farrero E, Félez MA, et al; Estudi del Factors de Risc d'Agudització de la MPOC Investigators. Risk factors of readmission to hospital for a COPD exacerbation: a prospective study. Thorax. 2003;58(2):100-105

12. Clini E, Venturelli E, Crisafulli E. Rehabilitation in COPD patients admitted for exacerbation. Pneumonol Alergol Pol. 2011;79(2):116-120.

13. Greening NJ, Williams JE, Hussain SF, et al. An early rehabilitation intervention to enhance recovery during hospital admission for an exacerbation of chronic respiratory disease: randomised controlled trial. BMJ. 2014;349:g4315.

14. Puhan MA, Spaar A, Frey M, et al. Early versus late pulmonary rehabilitation in chronic obstructive pulmonary disease patients with acute exacerbations: a randomized trial. Respiration. 2012;83(6):499-506.

15. Singh SJ, ZuWallack RL, Garvey C; American Thoracic Society/ European Respiratory Society Task Force on Pulmonary Rehabilitation. Learn from the past and create the future: the 2013 ATS/ERS statement on pulmonary rehabilitation. Eur Respir J. 2013;42:1169-1174.
16. Costi S, Di Bari M, Pillastrini P, et al. Short-term efficacy of upperextremity exercise training in patients with chronic airway obstruction: a systematic review. Phys Ther. 2009;89(5):443-455.

17. Janaudis-Ferreira T, Hill K, Goldstein R, Wadell K, Brooks D. Arm exercise training in patients with chronic obstructive pulmonary disease: a systematic review. J Cardiopulm Rehabil. 2009;29(5):277-283.

18. Enright SJ, Unnithan VB, Heward C, Withnall L, Davies DH. Effect of high-intensity inspiratory muscle training on lung volumes, diaphragm thickness, and exercise capacity in subjects who are healthy. Phys Ther. 2006;86(3):345-354.

19. Fernandes M, Cukier A, Feltrim MI. Efficacy of diaphragmatic breathing in patients with chronic obstructive pulmonary disease. Chron Respir Dis. 2011;8(4):237-244.

20. Hill K, Patman S, Brooks D. Effect of airway clearance techniques in patients experiencing an acute exacerbation of chronic obstructive pulmonary disease: a systematic review. Chron Respir Dis. 2010;7(1):9-17.

21. Kodric M, Garuti G, Colomban M, et al. The effectiveness of a bronchial drainage technique (ELTGOL) in COPD exacerbations. Respirology. 2009;14(3):424-428.

22. Seymour JM, Moore L, Jolley CJ, et al. Outpatient pulmonary rehabilitation following acute exacerbations of COPD. Thorax. 2010;65(5):423-428.

23. Ko FW, Dai DL, Ngai J, et al. Effect of early pulmonary rehabilitation on health care utilization and health status in patients hospitalized with acute exacerbations of COPD. Respirology. 2011;16(4):617-624.

24. Chow JS, Leung AS, Li WW, Tse TP, Sy HY, Leung TF. Airway inflammatory and spirometric measurements in obese children. Hong Kong Med J. 2009;15:346-352.

25. Borg G. Psychophysical scaling with applications in physical work and the perception of exertion. Scand J Work Environ Health. 1990;16(1): 55-58.

26. Skinner JS, Hutsler R, Bergsteinova V, Buskirk ER. The validity and reliability of a rating scale of perceived exertion. Med Sci Sports. 1973; 5(2):94-96.

27. Mutalithas K, Watkin G, Willig B, Wardlaw A, Pavord ID, Birring SS. Improvement in health status following bronchopulmonary hygiene physical therapy in patients with bronchiectasis. Respir Med. 2008; 102(8):1140-1144.

28. Enright PL. The six-minute walk test. Respir Care. 2003;48:783-785.

29. ATS Committee on Proficiency Standards for Clinical Pulmonary Function Laboratories. American Thoracic Society statement: guidelines for the six-minute walk test. Am J Respir Crit Care Med. 2002;166:111.

30. Clini EM, Crisafulli E, Costi S, et al. Effects of early inpatient rehabilitation after acute exacerbation of COPD. Respir Med. 2009;103(10): 1526-1531.

31. Lareau SC, Yawn BP. Improving adherence with inhaler therapy in COPD. Int J Chron Obstruct Pulmon Dis. 2010;5:401-406.

32. Nishimura K, Yasui M, Nishimura T, Oga T. Clinical pathway for acute exacerbations of chronic obstructive pulmonary disease: method development and five years of experience. Int J Chron Obstruct Pulmon Dis. 2011;6:365-372.

33. Sridhar M, Taylor R, Dawson S, Roberts NJ, Partridge MR. A nurse led intermediate care package in patients who have been hospitalised with an acute exacerbation of chronic obstructive pulmonary disease. Thorax. 2008;63(3):194-200.
International Journal of COPD

\section{Publish your work in this journal}

The International Journal of COPD is an international, peer-reviewed journal of therapeutics and pharmacology focusing on concise rapid reporting of clinical studies and reviews in COPD. Special focus is given to the pathophysiological processes underlying the disease, intervention programs, patient focused education, and self management protocols.

\section{Dovepress}

This journal is indexed on PubMed Central, MedLine and CAS. The manuscript management system is completely online and includes a very quick and fair peer-review system, which is all easy to use. Visit http://www.dovepress.com/testimonials.php to read real quotes from published authors. 